\title{
INGUINAL SWELLING DUE TO RARE EXTERNAL SUPRAVESICAL HERNIA - A CASE REPORT
}

\author{
Gopikrishna Dharmapuri' ${ }^{1}$, Arunprasath Sivaraman², Grey Bernard Francis ${ }^{3}$
}

${ }^{1}$ Assistant Professor, Department of General Surgery, Rajah Muthiah Medical College and Hospital, Annamalai Nagar. ${ }^{2}$ Final Year Post Graduate, Department of General Surgery, Rajah Muthiah Medical College and Hospital, Annamalai Nagar. ${ }_{3}^{3}$ Final Year Post Graduate, Department of General Surgery, Rajah Muthiah Medical College and Hospital, Annamalai Nagar.

\section{ABSTRACT}

\section{BACKGROUND}

Supravesical hernia is rare. The first case of supravesical hernia, according to Keynes, was reported by Sir Astley Cooper in 1804. It is of two types: internal and external supravesical hernia. Here we are presenting a 76-year-old male presented with a left inguinal swelling, which was diagnosed as external supravesical hernia per-operatively.

\section{KEYWORDS}

Supravesical Hernia, Inguinal Swelling.

HOW TO CITE THIS ARTICLE: Dharmapuri G, Sivaraman A, Francis GB. Inguinal swelling due to rare external supravesical hernia a case report. J. Evolution Med. Dent. Sci. 2016;5(87):6519-6520, DOI: 10.14260/jemds/2016/1473

\section{BACKGROUND}

Supravesical hernia is a rare phenomenon where the intraabdominal content either intestine or omentum protrudes through the supravesical fossa, a triangular area bounded laterally and above by median and medial umbilical ligaments and below by the peritoneal reflection that passes from the anterior abdominal wall to the dome of the bladder. A hernia starting in this fossa may protrude through the abdominal wall as a direct inguinal hernia (External supravesical hernia) or it remains within the abdomen, passing into spaces around the bladder (Internal supravesical hernia).

\section{CASE REPORT}

A 76-year-old male presented with complaints of painful swelling over left groin for the past 2 weeks. No history suggestive of intestinal obstruction, urinary abnormalities, malignant or inflammatory pathology. On examination patient was conscious, oriented, afebrile and well hydrated; BP 190/110 mmHg, PR 72/min. CBC, RFT, Serum electrolytes, LFT were within normal limits. A swelling over left inguinal region $5 \times 5 \mathrm{~cm}$ present $1 / 2$ inch above and lateral to pubic tubercle, no warmth with mild tenderness, irreducible, no cough impulse with restricted mobility. USG Abdomen showed left-sided inguinal hernia. Provisionally diagnosed as leftsided irreducible indirect inguinal hernia/left-sided encysted hydrocele of the cord. Under local anaesthesia left inguinal incision was placed, incision deepened in layers, on opening external oblique a $3 \times 3 \mathrm{~cm}$ external supravesical hernia sac identified $2 \mathrm{~cm}$ above and lateral to pubic tubercle. The hernia sac was inadvertently opened, which contains small intestine as content which was healthy with a narrow neck of $1.5 \mathrm{~cm}$ in diameter. Content was reduced, sac closed with 2-0 vicryl and peritonealised, defect closed with 1-0 prolene. Left

Financial or Other, Competing Interest: None.

Submission 25-09-2016, Peer Review 18-10-2016,

Acceptance 25-10-2016, Published 29-10-2016.

Corresponding Author:

Dr. Arunprasath Sivaraman,

Room No. 231, PG Doctors Mens' Hostel,

RMMCH, Annamalai Nagar,

Chidambaram-608002, Tamilnadu.

E-mail: sap_170@yahoo.co.in

DOI: $10.14260 /$ jemds $/ 2016 / 1473$

\section{(c) $(1)$}

herniorrhaphy done and wound closed in layers. Postoperative period was uneventful and patient discharged on fourth post-op day.

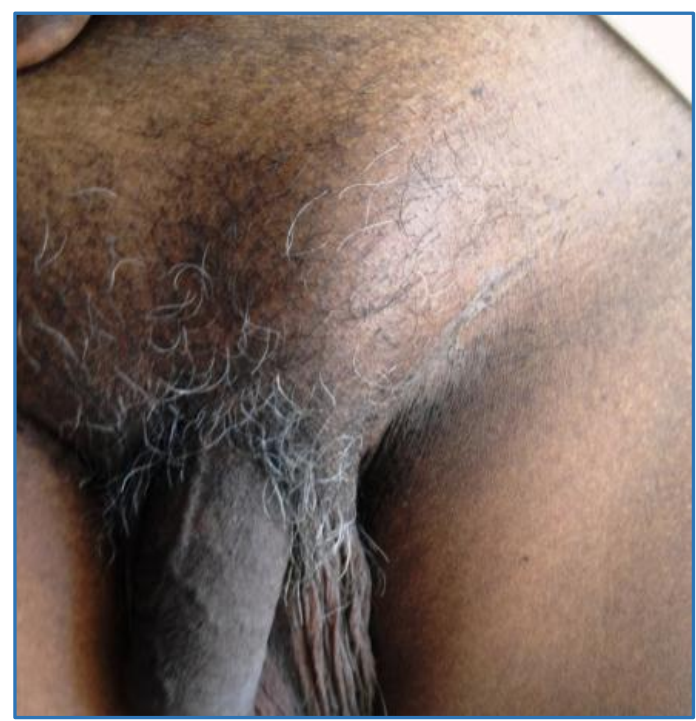

Figure 1. Pre-Op Picture

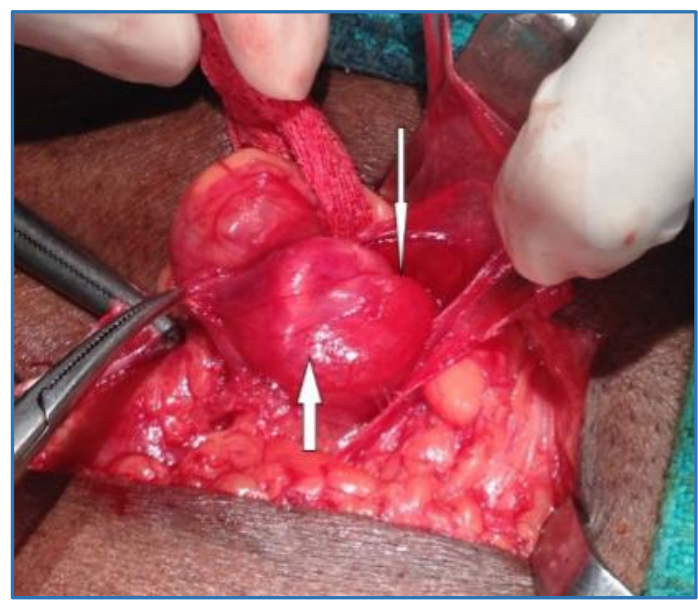

Figure 2. Intra Op. Picture showing Opened Sac with Narrow Neck (Thin Arrow), Small Intestine as Content (Thick Arrow) 


\section{DISCUSSION}

The supravesical fossa is the area of abdominal wall between remnant of urachus (Median umbilical ligament) and remnant of left or right umbilical artery (medial umbilical ligament). The inferior boundary is formed by a peritoneal fold, part of which is the transverse fold of the bladder (Fig. 3). The fossa may go on to form a deep diverticulum. These supravesical diverticula may herniate in several directions. Those in the superior portion of the supravesical fossa usually result in external hernias, while those arising in the inferomedial part may become lodged in the prevesical space of Retzius to form an internal hernia. The internal hernia in turn can be prevesical, paravesical, lateral or intravesical.1-3 When the bladder apex is weakened by a defective closure of the urachus, the diverticulum may herniate directly into the bladder forming intravesical type of internal supravesical hernia. 2,3

Pre-operative diagnosis of this condition is very difficult. In our case, the diagnosis was made only during laparotomy. In patients presenting with small bowel obstruction without any history of previous abdominal operations and no obvious external hernias are detected, pre-operative investigations may be very helpful in diagnosing this condition. $\mathrm{CT}^{4}$ or MRI ${ }^{5}$ scan may possibly diagnose this condition.

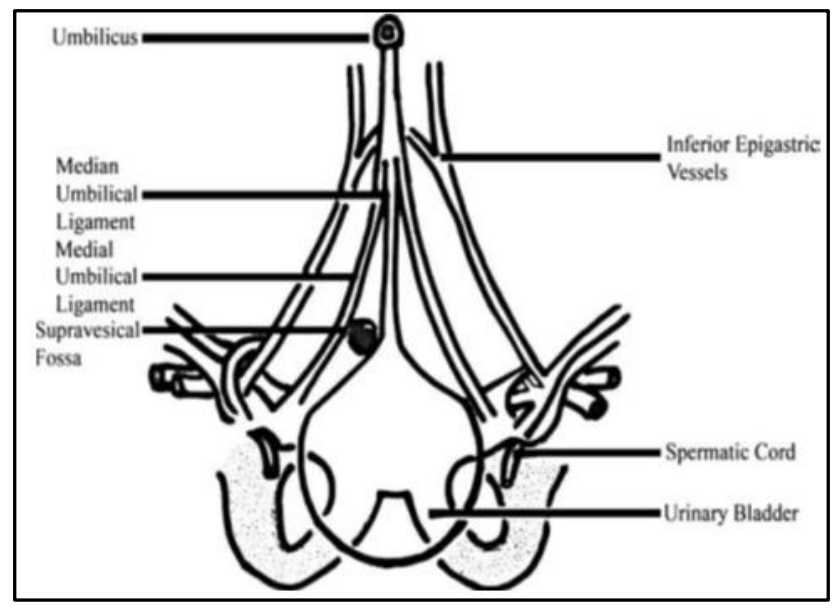

Figure 3. Diagram showing Anatomical Location of Supravesical Hernia

Cystoscopy $^{2}$ may show a tunnel shaped deformity in the bladder wall. Supravesical hernia can be seen on herniography 6 and in the consecutive series of 1000 cases Gullmo described 183 external and 1 internal supravesical hernia. However, this method of investigation is relatively new and not widely available, which may explain the paucity of reports of supravesical hernias. This condition has been reported to be diagnosed and treated laparoscopically. ${ }^{7}$ The majority of the recorded cases have been subjected to an exploratory laparotomy. The treatment is release of the intestinal obstruction and closing the hernial defect. Most authors advise against attempts to excise the hernia sac and think that freshening the edges of the ring with closure of the defect using continuous or interrupted stitches with nonabsorbable sutures is sufficient. 2,8

\section{CONCLUSION}

The present case illustrates the diagnostic dilemma in an inguinal swelling that is difficult to diagnose preoperatively. ${ }^{8-11}$ We suggest that a supravesical defect incidentally found during routine surgical exploration of the pelvis should be sutured to avoid incarceration of the bowel. The case reiterates the difficulty in diagnosing this rare hernia and calls attention to the entity as an unusual cause of inguinal swelling.

\section{REFERENCES}

1. Skandalakis JE, Gray SW, Burns WB, et al. Internal and external supravesical hernia. Am Surg 1976;42(2):142-6.

2. Sawyers JL, Stephenson SE. Internal supravesical hernia: report of the first successful operative repair of the intravesical type. Surgery 1957;42(2):368-74.

3. Barnes DR, Dreyer J. Internal supravesical hernia: report of a case presenting with bladder symptoms. Br J Surg 1953;40(163):508-9.

4. Sasaya T, Yamaguchi A, Isogai M, et al. Supravesical hernia: CT diagnosis. Abdom Imaging 2001;26(1):89-91.

5. Chou CK, Liu GC, Chen LT, et al. The use of MRI in bowel obstruction. Abdom Imaging 1993;18(2):131-5.

6. Gullmo A. Herniography. The diagnosis of hernia in the groin and incompetence of the pouch of douglas and pelvic floor. Acta Radiol Suppl 1980;361:1-76.

7. Mehran A, Szomstein S, Soto F, et a. Laparoscopic repair of an internal strangulated supravesical hernia. Surg Endosc 2004;18(3):554-6.

8. Koksoy FN, Soybir GR, Bulut TM, et al. Internal supravesical hernia: report of a case. Am Surg 1995; 61(11):1023-4.

9. Sozen I, Nobel J. Inguinal mass due to an external supravesical hernia and acute abdomen due to an internal supravesical hernia: a case report and review of the literature. Hernia 2004;8(4):389-92.

10. Abdullah TI, Pearson HJ. Strangulated internal supravesical hernia: a diagnostic problem. Eur J Surg 1997;163(11):875-6.

11. Tretbar LL, Gustafson GE. Internal supravesical hernia: a rare hernia causing small bowel obstruction. Am J Surg 1968;116(6):907-8. 